Research Article

\title{
Evaluation of Health Resource Allocation Efficiency Based on Data Envelopment Analysis 2014-2018 in Two Dimensions of Time-Region
}

\author{
Lina Liu, ${ }^{1}$ Wei Xu, ${ }^{1}$ Yixuan Su $\mathbb{D}^{2},{ }^{2}$ and Xv Zhou $\mathbb{D}^{2}$ \\ ${ }^{1}$ Shenyang University of Technology, Shenyang, China \\ ${ }^{2}$ Dalian Medical University, Dalian, China \\ Correspondence should be addressed to Yixuan Su; smmdum@163.com and Xv Zhou; 1049681444@qq.com
}

Received 27 October 2021; Accepted 19 November 2021; Published 23 December 2021

Academic Editor: Daqing Gong

Copyright (C) 2021 Lina Liu et al. This is an open access article distributed under the Creative Commons Attribution License, which permits unrestricted use, distribution, and reproduction in any medium, provided the original work is properly cited.

\begin{abstract}
Since the new health care reform, China's health care system has become increasingly mature and perfect, and the health awareness and needs of residents have also increased, which has raised higher requirements for the scientific understanding of the current status of health care resource allocation and making it achieve the goal of efficient operation. This paper evaluates the allocation of health resources in China from 2014 to 2018 in two dimensions: time and space by reviewing the China Health and Health Statistical Yearbook from 2014 to 2020, collecting data on the number of medical institutions, number of beds, per capita medical budget expenditure, number of consultations, and bed utilization rate during the study time interval, and analyzing them using data envelopment analysis. The results show that there are regional differences in the supply level of medical and health resources in China. Although the supply level is mainly on the rise, there are differences in the supply level of medical and health resources among provinces. The polarization phenomenon exists between eastern, central, and western regions, the urban and rural areas, the urban hospitals, and grassroots-level health care organizations.
\end{abstract}

\section{Introduction}

Medical and health resources refer to the general term for the human, material, and financial resources provided by the society to the health sector under certain social and economic conditions including hard resources and soft resources [1]. Medical and health hard resources generally refer to tangible resources such as medical and health manpower and material resources; medical and health soft resources refer to intangible resources such as medical technology, medical education, health information, health policies, and health regulations. The health resources allocation refers to how the government or the market allocates health resources in different fields, regions, departments, projects, and populations fairly and efficiently, so as to maximize the social and economic benefits of health resources.

In 2015, the executive meeting of the State Council discussed and approved the "National Medical and Health
Service System Planning Outline (2015-2020)." The document pointed out that China has established a health service system covering both urban and rural areas, consisting of hospitals, public health institutions, and grass-roots-level medical and health institutions at present. However, due to the general imbalance of economic development between various regions, coupled with geographical factors, religious factors, transportation factors, etc., there are general differences in medical concepts and consumption levels in various regions, which brings numerous problems-insufficient total resources, quality to be improved, unreasonable layout structure, fragmentation of the service system, and unreasonable expansion of the scale of some public hospitals-between the medical and health services of the economic and social development and the people's increasing increasing demand and the allocation of current medical and health resource [2]. How to rationally 
allocate existing health resources and achieve high-efficiency utilization so as to meet the people's demand for the continuous increase in the quantity and quality of our countrys medical and health services have become the focus of my country's health field in recent years. This paper analyzes the relevant situation of our country's health resource allocation efficiency from 2014 to 2018 through data envelopment analysis, and actively explores measures to improve the allocation of health resources, so as to provide scientific decision-making basis for better allocation of health resources in our country.

In terms of measurement methods, foreign scholars mostly use the data envelopment analysis method combined with other model-assisted analysis. Jordi et al. used the twostage efficiency analysis of Simar and Wilson's dual-lead data envelopment analysis to investigate how effectively 172 countries have transformed health expenditures into an UHC output (measured by service coverage and financial risk protection) [3]; Madjid et al. used structural equation modeling and Z-DEA to evaluate medical equipment suppliers' performance. Compared with foreign countries, I have also explored the application of DEA method in the field of public health [4]; Jing et al. used data envelopment analysis (DEA) to study the number of sickbeds and inputoutput efficiency of health technicians in clinical departments of a third-class Grade A Traditional Chinese medicine hospital in Jiangsu Province in 2016, so as to control the overdevelopment of clinical departments and waste of health resource allocation [5]; Zhu et al. applied the data envelopment analysis (DEA) method to calculate the overall efficiency, pure technical efficiency, and scale efficiency of the basic public health service projects of various institutions in 2017 to conduct evaluation and analysis [6]; Pang et al. are input-oriented and first used the DEA-CCR model to calculate the comprehensive efficiency of 15 maternity and child care hospitals in Guangxi City, used the BCC model to obtain pure technical efficiency and scale efficiency, and used the super-efficiency model to rank the efficiency values [7]. Finally, I use the Malmquist index model to analyze the dynamic efficiency changes from 2015 to 2017.

In terms of research objects, most scholars at home and abroad are pertinent in their selection, and tend to conduct analysis and research on specific industries in specific regions. Darabi et al. used the DEA method to evaluate the birth result of the US health system [8]; Coluccia et al. adopted the data envelopment analysis (DEA) method to construct suitable indicators based on the differences between national geographic regions to evaluate the ecological efficiency of the Italian agricultural sector [9]; Bi and Wang used data envelopment analysis and Tobit regression model to sort out the financial and operational data of 60 tertiary public hospitals in Jiangsu Province in 2014 and compare the efficiency differences of different regions and types of tertiary hospitals, so as to allocate health resources rationally. Provide evidence [10]; Zhang et al. used factor analysis to select input and output indicators, and then used DEA to analyze the data related to health resources of Chinese medicine hospitals in 31 provinces and cities across the country in 2017, and further to provide a reference for further improving the efficiency of health resource allocation in Chinese medicine hospitals in accordance with Ref. [11].

In summary, DEA has been widely used in the medical and health field, and its utilization rate has gradually increased in recent years. The purpose of this study was to analyze the current situation of descriptive research on the allocation of medical and health resources in China from 2014 to 2018. Therefore, after doing a lot of literature research and based on the available data, this paper selects our country's relevant health data from 2014 to 2018 for data envelopment analysis, establishes a VRS-BCC (variable returns to scale) model to study our country's medical and health resources allocation in the said period. Combined with the characteristics of population distribution and geographical environmental factors, this paper explores regional differences and puts forward relevant suggestions and measures.

\section{Data Description and Model Construction}

2.1. Data Description. This paper selects data related to medical and health resources in 31 provinces, municipalities, and autonomous regions except Hong Kong, Macau Special Administrative Region, and Taiwan from 2014 to 2018 as the research object. According to the division of different regions in the China Health Statistical Yearbook compiled by the National Health Commission and published by The Peking Union Medical College Press, it divides the above 31 provinces and cities into three parts: the east, the central, and the west. The eastern region includes 11 provinces: Beijing, Tianjin, Hebei, Liaoning, Shanghai, Jiangsu, Zhejiang, Fujian, Shandong, Guangdong, and Hainan; the central region includes 8 provinces: Shanxi, Jilin, Heilongjiang, Anhui, Jiangxi, Henan, Hubei, and Hunan; the western region includes 12 provinces: Inner Mongolia, Chongqing, Guangxi, Sichuan, Guizhou, Yunnan, Tibet, Shaanxi, Gansu, Qinghai, Ningxia, and Xinjiang. The data come from the "China Health Statistics Yearbook" (2014-2020).

2.2. Model Construction. Data Envelopment Analysis (DEA) was first proposed in 1978 by famous American Operations Researchers A. Charnes, WWCooper, and E. Rhodes. A nonparametric test method was developed based on the concept of relative efficiency evaluation. After certain researches and extensive applications, there are many different evaluation models such as CCR (Chames Cooper Rhodes) model, BCC (Banker Charnes Cooper) model, ST (Seiford Thrall) model, and Malmquist model. This paper adopts the static CCR model and BCC model [12].

2.2.1. CCR Model. The CCR model was proposed by Charnes, Cooper, and Rhodes in 1978. It can calculate the efficiency of resource allocation under constant returns to scale [13]. We can simply invert the CCR model, take the efficiency index of the $j_{0}$ decision-making unit as the goal, take the efficiency of all decision-making units as the constraint, and the following model can be obtained, as shown in: 


$$
\begin{aligned}
& \max \quad h_{j 0}=\frac{\sum_{r=1}^{s} u_{r} y_{r j_{0}}}{\sum_{i=1}^{m} v_{i} x_{i j_{0}}} \\
& \text { s.t. } \quad \frac{\sum_{r=1}^{s} u_{r} y_{r j}}{\sum_{i=1}^{m} v_{i} x_{i j}} \leq 1, \quad j=1,2, \ldots, n \\
& \quad u \geq 0, v \geq 0 .
\end{aligned}
$$

Among them, $x_{i j}$ represents the total input of the $j$-th decision-making unit to the $i$-th input element, and $y_{r j}$ represents the total output of the $r$-th product in the $j$-th decision-making unit, $v_{i}$ and $u_{r}$, respectively, refer to the $i$-th type of input and the $r$-th type. The weight coefficient of the type output.

Let $\omega=\left(1 / \nu^{T} x_{0}\right) v$ and $\mu=\left(1 / v^{T} x_{0}\right) u$ transform through Charnes-Cooper, incorporate the slack variable $s^{+}$and the residual variable $s^{-}$, the model can be simplified to the formula:

$$
\begin{aligned}
& \min \theta \\
& \sum_{j=1}^{n} \lambda_{j} y_{j}+s^{+}=\theta x_{0} \\
& \text { s.t. } \sum_{j=1}^{n} \lambda_{j} y_{j}+s^{-}=\theta y_{0} \\
& \lambda_{j} \geq 0, \quad j=1,2, \ldots, n \\
& s^{+} \geq 0, s^{-} \leq 0 .
\end{aligned}
$$

2.2.2. BCC Model. The CCR model is obtained under the premise of constant return to scale, but the return to scale of technological innovation is not fixed. The unequal competition in reality will also cause certain decision-making units to fail to operate at the optimal scale. In 1984, Banker, Charnes, and Cooper extended the DEA analysis, which only discussed fixed scale benefits, and proposed the BCC model.

The BCC model takes the case of variable returns to scale (VRS) into account, that is, the measurement of technology efficiency (TE) will be affected by scale efficiency (SE) when some decision-making units are not operating at the optimal scale. When constructing the BCC model, we need to assume that the return to scale is variable, make simple improvements to the constraints of the CCR model, and increase the assumption of convexity: $\sum \lambda_{j}=1, j=1,2, \ldots, n$, And we can get formula (2).

2.2.3. Indicator Selection. It can meet DEA's requirements for the number of indicators, availability, stability, and independence [14]. In summary, cluster analysis, correlation analysis, and coefficient of variation analysis are performed on the data indicators, and finally the paper selects the number of medical and health institutions, the number of sickbeds, the per capita medical and health budget expenditure, the number of consultations and treatments, and the utilization rate of hospital sickbeds, as shown in Table 1.
(1) Input Indicators. Public health expenditure is the most direct embodiment of measuring public health financial investment [15]. In order to highlight my country's medical and health service resources more intuitively, we select medical and health institutions that comply with relevant national laws and regulations including hospitals, primary medical and health institutions, professional public health institutions, the sum of other medical and health institutions, and the number of beds. Some authors also choose other indicators as input variables, such as $\mathrm{Li}$, who directly takes the per capita public health financial expenditure of local governments as an input indicator [16]. Since this study mainly discusses the efficiency evaluation of government public health expenditure, economic factors play a vital role in whether the public accepts medical and health services or the price of medical and health services. Therefore, the total health expenditure per capita, which is the ratio of the total health expenditure in a certain year to the average population in the same period, is selected as the input indicator.

(2) Output Indicators. In order to better express the status of people seeking medical and health services on their own, according to the investment indicators, the number of patients and sickbed utilization rate of outpatient services in medical and health institutions can be selected as output indicators.

From the above description, we can define Sick bed utilization rate as formula:

$$
\frac{\text { actual total bed days occupied }}{\text { actual open total bed days }} \times 100 \% \text {. }
$$

\section{Analysis of the Empirical Results}

It is known that the overall technical efficiency consists of two parts, overall technical efficiency = pure technical efficiency $\times$ scale efficiency [17]. This study collected data in 31 provinces and cities across the county by using the EDA to analyze the medical and health resource data, so as to explore the changing trend of health resources in space and time. When analyzing the space dimension, it focuses on the cross-sectional analysis of health resource allocation in 31 provinces and cities in 2018, and the partition considers the overall areas and the local areas to compare the east, the middle, and the west. While the time dimension focuses on the longitudinal trend research from 2014 to 2018 combined with the regional differences, it measured and calculated the medical and health efficiency of all provinces (regions and municipalities) in China, and put forward policy suggestions to promote efficiency.

3.1. Space Dimension. According to the evaluation indicators selected in the earlier stage, the collected data of medical and health resources in 31 provinces and cities across the country in 2018 were analyzed for the efficiency of health resource allocation. The input-output indicator data in 31 provinces and cities in 2018 is shown in Table 2. And, we obtained the value of input-output health resources 
TABLE 1: Evaluation measure indicators of China's health resource allocation efficiency.

\begin{tabular}{lccc}
\hline & Indicators name & Symbolic representation & Measuring unit \\
\hline \multirow{3}{*}{ Input indicators } & Number of medical and health care institutions & X1 & School \\
& Number of sickbeds & X2 & Piece \\
Health expenditure per capita & X3 & Yuan \\
\hline \multirow{2}{*}{ Output indicators } & Number of visits & Y1 & Visit \\
& Sickbed utilization rate & Y2 & Percentage \\
\hline
\end{tabular}

TABLE 2: Input-output indicator data of 31 provinces and cities in China in 2018.

\begin{tabular}{|c|c|c|c|c|c|}
\hline \multirow[b]{2}{*}{ Regions } & \multicolumn{3}{|c|}{ Input indicators } & \multicolumn{2}{|c|}{ Output indicators } \\
\hline & $\begin{array}{l}\text { Number of medical and } \\
\text { health care institutions }\end{array}$ & Number of sickbeds & $\begin{array}{l}\text { Health expenditure } \\
\text { per capita (yuan) }\end{array}$ & Number of visits & $\begin{array}{l}\text { Rate of utilization of } \\
\text { hospital sickbeds (\%) }\end{array}$ \\
\hline Beijing & 10336 & 127777 & 11609.06 & 248863924 & 82.6 \\
\hline Tianjin & 5962 & 68262 & 5698.41 & 122885315 & 79.8 \\
\hline Hebei & 84651 & 430079 & 3561.06 & 432278975 & 81.3 \\
\hline Shanxi & 42162 & 218441 & 3282.00 & 131456549 & 76.6 \\
\hline Inner Mongolia & 24564 & 161083 & 4272.88 & 107012004 & 71.4 \\
\hline Liaoning & 34238 & 313847 & 3966.09 & 199875532 & 73.8 \\
\hline Jilin & 22198 & 170332 & 4072.93 & 110419561 & 76.2 \\
\hline Heilongjiang & 20375 & 262575 & 3728.40 & 112508919 & 74.5 \\
\hline Shanghai & 5597 & 146454 & 9495.89 & 275599946 & 96.2 \\
\hline Jiangsu & 34796 & 516015 & 5012.01 & 617216469 & 85.7 \\
\hline Zhejiang & 34119 & 350191 & 5433.29 & 681331526 & 88.4 \\
\hline Anhui & 26435 & 347395 & 3159.72 & 333159292 & 83.1 \\
\hline Fujian & 27788 & 202211 & 3941.89 & 248996411 & 82.8 \\
\hline Jiangxi & 37029 & 267135 & 3170.63 & 236277434 & 84.8 \\
\hline Shandong & 83616 & 629722 & 4121.35 & 674640523 & 80.7 \\
\hline Henan & 70734 & 640147 & 3227.66 & 610202911 & 88.1 \\
\hline Hubei & 35515 & 403300 & 3951.21 & 353825758 & 92.3 \\
\hline Hunan & 57230 & 506330 & 3601.22 & 280980963 & 83.7 \\
\hline Guangdong & 53900 & 545196 & 4581.96 & 891797672 & 82.2 \\
\hline Guangxi & 33679 & 277357 & 3278.54 & 261311747 & 90.0 \\
\hline Hainan & 5417 & 49764 & 4307.91 & 52526284 & 78.4 \\
\hline Chongqing & 21057 & 231806 & 4430.65 & 175482812 & 82.2 \\
\hline Sichuan & 83756 & 631763 & 3900.12 & 560264451 & 89.4 \\
\hline Guizhou & 28511 & 264986 & 3352.12 & 175797327 & 81.5 \\
\hline Yunnan & 25587 & 311899 & 3425.52 & 282443267 & 83.8 \\
\hline Tibet & 6940 & 17063 & 4881.82 & 16342879 & 64.8 \\
\hline Shaanxi & 35404 & 265814 & 4508.42 & 208989669 & 81.7 \\
\hline Gansu & 26697 & 181172 & 3303.72 & 126888408 & 82.3 \\
\hline Qinghai & 6513 & 41443 & 5107.20 & 26593571 & 74.1 \\
\hline Ningxia & 4397 & 40971 & 4992.64 & 43583230 & 81.1 \\
\hline Xinjiang & 18376 & 186426 & 4843.23 & 120319753 & 87.9 \\
\hline
\end{tabular}

allocation efficiency in 31 provinces and cities across the country in 2018, which is shown in Table 3, by using the DEAP2.1 software.

As can be seen from Table 3, it is known from the latest data analysis that there are 13 regions whose overall efficiency is below the national average level (0.926) including Shandong, Hubei, Hunan, Chongqing, Sichuan, Shaanxi, Qinghai, Xinjiang, Shanxi, Inner Mongolia, Liaoning, Jilin, and Heilongjiang, accounting for about $41.9 \%$ of the total. In 2018, the "Return to scale" of Beijing, Zhejiang, Anhui, Henan, Guangdong, Tianjin, Guangxi, Hainan, Tibet, Gansu, Ningxia, and Shanghai was DEA effectiveness, accounting for $38.7 \%$ of the total as shown in Figure 1; there are 5 regions with weak DEA effectiveness in Fujian, Jiangxi,
Hubei, Sichuan, and Xinjiang, accounting for about $16.1 \%$ of the total; there are 14 Non-DEA effectiveness regions, accounting for $45.2 \%$ of the total. It shows that there are some problems such as input surplus, insufficient output, and too large or too small scale in these regions. Among them, the Liaoning province has the lowest comprehensive efficiency (only 0.718 ), and it only displayed $71.8 \%$ of the efficiency level. In terms of return to scale, Hubei, Chongqing, Sichuan, Yunnan, and Xinjiang have diminishing returns to scale, indicating that the existing health resource allocation in these 5 provinces is uneconomic with high input, with the input being higher than the output, which should be properly controlled. Especially for the Liaoning Province, the most important reason for the DEA effectiveness is the 
TABLE 3: DEA effectiveness of health resource allocation efficiency in 31 provinces and cities across the country in 2018.

\begin{tabular}{|c|c|c|c|c|c|}
\hline Regions & Comprehensive efficiency & Pure technical efficiency & Scale efficiency & Return to scale & Relative effectiveness \\
\hline Beijing & 1.000 & 1.000 & 1.000 & - & Effectiveness \\
\hline Tianjin & 0.965 & 0.970 & 0.995 & irs & Non-DEA effectiveness \\
\hline Hebei & 1.000 & 1.000 & 1.000 & - & Effectiveness \\
\hline Shanxi & 1.000 & 1.000 & 1.000 & - & Effectiveness \\
\hline Inner Mongolia & 0.989 & 1.000 & 0.990 & irs & Weak-DEA effectiveness \\
\hline Liaoning & 0.975 & 1.000 & 0.975 & irs & Weak-DEA effectiveness \\
\hline Jilin & 0.872 & 0.900 & 0.970 & irs & Non-DEA effectiveness \\
\hline Heilongjiang & 1.000 & 1.000 & 1.000 & - & Effectiveness \\
\hline Shanghai & 0.890 & 1.000 & 0.890 & drs & Weak-DEA effectiveness \\
\hline Jiangsu & 0.847 & 0.878 & 0.964 & irs & Non-DEA effectiveness \\
\hline Zhejiang & 1.000 & 1.000 & 1.000 & - & Effectiveness \\
\hline Anhui & 1.000 & 1.000 & 1.000 & - & Effectiveness \\
\hline Fujian & 1.000 & 1.000 & 1.000 & - & Effectiveness \\
\hline Jiangxi & 1.000 & 1.000 & 1.000 & - & Effectiveness \\
\hline Shandong & 0.842 & 0.843 & 0.999 & drs & Non-DEA effectiveness \\
\hline Henan & 0.875 & 1.000 & 0.875 & drs & Weak-DEA effectiveness \\
\hline Hubei & 0.942 & 0.965 & 0.976 & irs & Non-DEA effectiveness \\
\hline Hunan & 0.973 & 0.976 & 0.996 & drs & Non-DEA effectiveness \\
\hline Guangdong & 1.000 & 1.000 & 1.000 & - & Effectiveness \\
\hline Guangxi & 0.767 & 0.790 & 0.971 & irs & Non-DEA effectiveness \\
\hline Hainan & 1.000 & 1.000 & 1.000 & - & Effectiveness \\
\hline Chongqing & 0.896 & 0.901 & 0.995 & irs & Non-DEA effectiveness \\
\hline Sichuan & 0.907 & 0.939 & 0.966 & irs & Non-DEA effectiveness \\
\hline Guizhou & 1.000 & 1.000 & 1.000 & - & Effectiveness \\
\hline Yunnan & 0.867 & 1.000 & 0.867 & drs & Weak-DEA effectiveness \\
\hline Tibet & 0.901 & 0.990 & 0.910 & irs & Non-DEA effectiveness \\
\hline Shaanxi & 0.765 & 0.858 & 0.892 & irs & Non-DEA effectiveness \\
\hline Gansu & 0.718 & 0.815 & 0.881 & irs & Non-DEA effectiveness \\
\hline Qinghai & 0.835 & 0.889 & 0.939 & irs & Non-DEA effectiveness \\
\hline Ningxia & 0.869 & 0.951 & 0.914 & irs & Non-DEA effectiveness \\
\hline Xinjiang & 1.000 & 1.000 & 1.000 & - & Effectiveness \\
\hline
\end{tabular}

low pure technology efficiency and low scale efficiency. Therefore, in health resources allocation, the province shall not only pay attention to the optimization of resource structure but also introduce more advanced diagnosis and treatment technology or management experience, so as to achieve the goal of providing ideal medical and health services.

The optimal combination of factors is a combination of factor inputs that produce a maximum production at a given cost or that produce a given production at a minimum cost. In order to guarantee the reasonable configuration of health resources in our country, it is necessary to let all the production factors achieve the state of this optimal combination. As can be seen in Table 4, the eastern, central, and western regions of China generally had a high overall level of health resource allocation from 2014 to 2018 , the central and western regions were in the state of increasing returns to scale from 2015 to 2017, showing a Constant-Rise-Constant development process. With the increasing input of the government and other subjects in health resources, it reached the optimal inputoutput state in 2018 and the eastern, central, and western regions all were relatively stable in the same year showing a good development trend in the early stage. According to the data in Table 4, the eastern regions of China have more years with DEA effectiveness, and the comprehensive efficiency is significantly higher than that of the central and western regions of China. It is almost in a relatively static state, and the structure and input-output reach the optimal combination, which is related to the backward economy and complex geographical environment in the central and western regions of China, and has a certain correlation with developed economy, high per capita consumption level, and higher education level in eastern regions of China.

3.2. Time Dimension. As can be seen in Table 5, the mean value of China's overall health resource allocation efficiency from 2014 to 2018 was 0.997 , and the comprehensive efficiency score in the recent five years was generally high. Year 2014, Year 2017, and Year 2018 are the years with DEA effectiveness, indicating that China's input of health resources has been fully utilized during these years and it is at the forefront of production constructed with the best input and output. The comprehensive efficiency can be divided into pure technical efficiency and scale efficiency. In the figure, we can see that the fluctuation of pure technical efficiency curve is not obvious in the recent five years, but the fluctuation of scale efficiency is relatively large. The pure technical efficiency is always higher than scale efficiency from 2015 to 2016, and the difference reaches the maximum in 2015, and the relatively low scale efficiency has become the key factor restricting the comprehensive technical efficiency. 


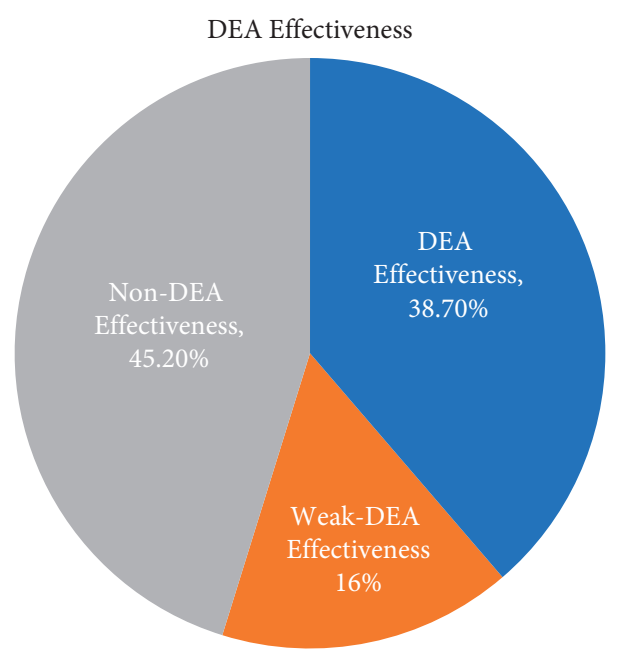

DEA Effectiveness

Weak-DEA Effectiveness

Non-DEA Effectiveness

FIGURE 1: DEA effectiveness of health resource allocation efficiency in 31 provinces and cities across the country in 2018.

TABLE 4: Comparison of health resource allocation efficiency in eastern, central and western regions of China from 2014 to 2018.

\begin{tabular}{|c|c|c|c|c|}
\hline \multirow{2}{*}{ Time } & \multirow{2}{*}{ Index } & \multicolumn{3}{|c|}{ Region } \\
\hline & & Eastern & Western & Centra \\
\hline \multirow{4}{*}{2014} & Comprehensive efficiency & 1.000 & 1.000 & 1.000 \\
\hline & Pure technical efficiency & 1.000 & 1.000 & 1.000 \\
\hline & Scale efficiency & 1.000 & 1.000 & 1.000 \\
\hline & Returns to scale & - & - & - \\
\hline \multirow{4}{*}{2015} & Comprehensive efficiency & 0.994 & 0.987 & 0.977 \\
\hline & Pure technical efficiency & 1.000 & 0.998 & 0.986 \\
\hline & Scale efficiency & 0.994 & 0.989 & 0.991 \\
\hline & Returns to scale & irs & irs & irs \\
\hline \multirow{4}{*}{2016} & Comprehensive efficiency & 1.000 & 0.995 & 0.989 \\
\hline & Pure technical efficiency & 1.000 & 1.000 & 0.990 \\
\hline & Scale efficiency & 1.000 & 0.995 & 0.998 \\
\hline & Returns to scale & - & Irs & irs \\
\hline \multirow{4}{*}{2017} & Comprehensive efficiency & 1.000 & 0.996 & 0.996 \\
\hline & Pure technical efficiency & 1.000 & 1.000 & 1.000 \\
\hline & Scale efficiency & 1.000 & 0.996 & 1.996 \\
\hline & Returns to scale & - & irs & irs \\
\hline \multirow{4}{*}{2018} & Comprehensive efficiency & 1.000 & 1.000 & 1.000 \\
\hline & Pure technical efficiency & 1.000 & 1.000 & 1.000 \\
\hline & Scale efficiency & 1.000 & 1.000 & 1.000 \\
\hline & Returns to scale & - & - & - \\
\hline
\end{tabular}

${ }^{*}:$ crste is the technical efficiency without considering the return to scale; vrste is the technical efficiency considering returns to scale; scale is scale efficiency considering returns to scale.

In 2016, it was weak DEA effectiveness, while in 2015, it was non-DEA effectiveness with $\mathrm{PTE}<1$ and $\mathrm{SE}<1$, and it can be clearly seen that the three curves on the way have obvious depressions in 2015, showing an obvious downward trend as shown in Figure 2. In economics, pure technical efficiency is the production efficiency of enterprises affected by factors such as management and technology, and scale efficiency often represents the production efficiency affected by enterprise scale factors. This means that, during this period, the utilization of China's medical and health institutions is unreasonable, and there are some problems in the actual health demand and supply. Under the current scale, the invested resources are not only insufficient but also not fully utilized, resulting in the unreasonable efficiency of health resource allocation and non-DEA effective results. And, it can be seen in 2015 and 2016 that health resources allocation has been showing increasing returns to scale, indicating that there is a shortage of total resources in the development of 
TABLE 5: Overall health resources allocation in China from 2014 to 2018.

\begin{tabular}{lccccc}
\hline Year & Comprehensive efficiency & Pure technical efficiency & Scale efficiency & Return to scale & Relative effectiveness \\
\hline 2014 & 1.000 & 1.000 & 1.000 & - & Effectiveness \\
2015 & 0.988 & 0.998 & 0.990 & irs & Non-DEA effectiveness \\
2016 & 0.998 & 1.000 & 0.998 & irs & Weak-DEA effectiveness \\
2017 & 1.000 & 1.000 & 1.000 & - & Effectiveness \\
2018 & 1.000 & 1.000 & 1.000 & Effectiveness \\
Mean value & 0.997 & 1.000 & 0.998 & \\
\hline
\end{tabular}

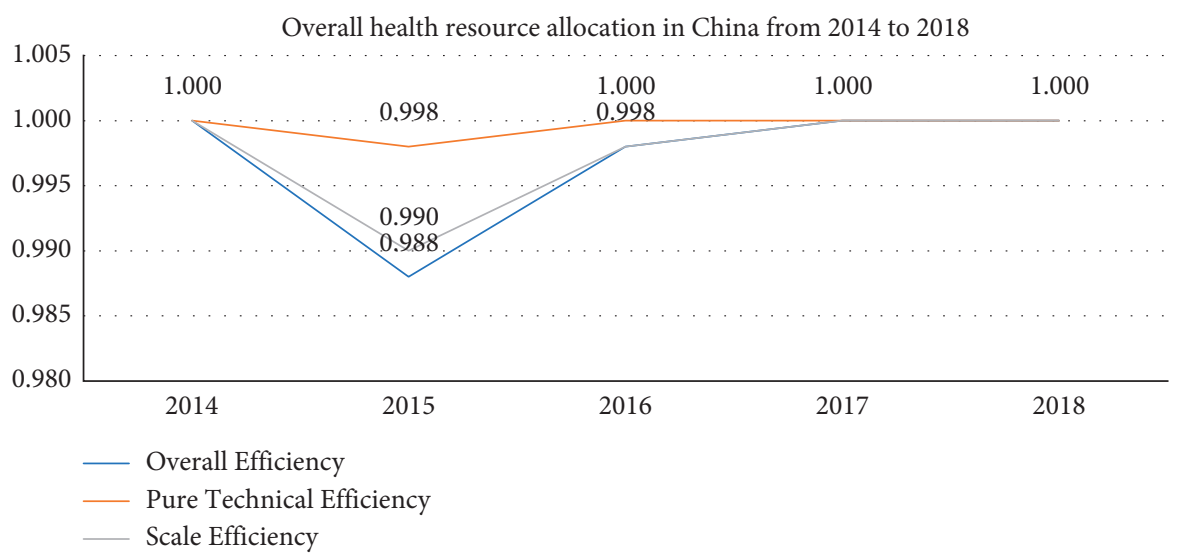

Figure 2: Line chart of China's overall health resource allocation from 2014 to 2018.

medical and health services in China and the relevant government departments should increase the investment of health resources in order to obtain better allocative efficiency.

\section{Discussion}

According to the above empirical analysis, there are regional differences in the supply level of medical and health resources in China [18]. Although the supply level is mainly on the rise, there are differences in the supply level of medical and health resources among provinces. According to the result, most provinces and cities in the central region and western region show the Non-DEA effectiveness, meanwhile, the three northeastern provinces were all in the same state. This phenomenon is mainly caused by the internal differences of the different economic region. Due to the existence of external environmental factors such as region and climate, the economic level is relatively backward, and the three provinces in northeast China are also backward due to the serious population loss in recent years, which leads to the depression of economic development. However, among these provinces and cities, Shandong Province located in the eastern coastal area also presents non-DEA effectiveness, and its comprehensive efficiency, pure technical efficiency, and scale efficiency are all less than 1 . Short supply of the existing medical and health resources may greatly be caused by the large size of population in the economically developed region, the strong health consciousness of residents, strong willingness to seek medical treatment, and high demand for life and health. We should make full use of positive factors and multisectoral cooperation to promote the rational configuration of health resources. Thus, economic development and urbanization can promote the supply level of medical and health resources.

Although the comprehensive efficiency of the allocation of resources in our country is on a rising trend, the differences are significant between regions. The polarization phenomenon exists between eastern, central, and western regions, the urban and rural areas, the urban hospitals, and grassrootslevel health care organizations, which led to our country existing primary health care service system resource shortage, and unreasonable resource allocation structure of medical and health service system. With the change of the disease spectrum and the aggravation of the aging of the social population, the health needs of residents in different regions and at different levels have increased. The talent loss of primary medical institutions, the first choice of large hospitals for patients with diseases, and the regional differences of health resources make the reasonable allocation of health resources in China face certain risks and challenges [19].

\section{Conclusion}

Therefore, through the DEA analysis of the spatial dimension and time dimension of the allocation efficiency of health resources in China from 2014 to 2018, the following suggestions are put forward on how to improve the allocation efficiency of health resources in China and ensure its stable development: 
5.1. Screening Specific Indicators and Adopting Scientific Measurement Methods Can Accurately Fill the Regional Weaknesses. The evaluation results of the health resource allocation efficiency have certain guidance for the development of China's medical and health undertakings. Usually, according to the obtained analysis results, corresponding policies and decisions should be made, and suggestions and measures for rectification and repair should be put forward. Therefore, it is very important to select specific indicators and adopt scientific measuring methods during the process of measuring the efficiency of health resource allocation. Our country is a complex but harmonious power, which leads to a regional economy or the environment due to the vast differences in external factors such as climate. So we must give full consideration to the regional economic differences, different latitudes of natural environmental factors, population density and age groups, as well as the degree of demand for medical and health services in different regions and other variables while screening specific measures, and we shall use reasonable indicators and scientific measuring methods to do accurate positioning. On the national level, national policies and funds should be gradually tilted towards the central and western regions or regions with slowing economic and social development, and the relationship between increment and stock should be handled well. Increment should be allocated more to the central and western regions or regions with backward economic and social development to improve the level of equalization [20]. According to the conclusion in this paper, the investment can be continually increased for provinces and cities with increasing returns to scale in a certain period. For the poor and remote areas, it is necessary to pay attention to the investment in technology, speed up the introduction of talents, update equipment, and promote talent to the grass-roots level to narrow the disparity of health resource allocation. With the goal of meeting the different medical and health service needs of local residents, scientific and rational health resource allocation and health planning are carried out according to some factors, such as geography, socioeconomic development level, and discipline layout [21] to bring new power for the regional health management and technological progress.

5.2. Continue to Promote the Construction of "Internet + Medical and Health" and Make Use of Contemporary Science and Technology to Open Up a New Situation of $5 G$ Sharing of Health Resources. From 2014 to 2018, the eastern, central, and western regions of China had a relatively high overall level of health resource allocation. Among them, the central and western regions were in a state of increasing returns to scale from 2015 to 2017, indicating that the current medical and health resource allocation in this region was uneconomic. Therefore, unbalanced regional economic development and uneven the development level are the major problems in the construction of the current medical and health service system. Due to the lack of health resources, the areas with low economic level, complex geographical environment, and a real need for medical and health resources and services such as western China or minority areas have some problems with the fairness and accessibility of the allocation of health resources. As a result, many patients who suffer from diseases are unable to seek medical treatment in time, which greatly affects the life expectancy and quality of life of patients. It is imperative to make use of contemporary science and technology to continuously promote the construction of "Internet + Medical and Health" and open up a new situation of sharing health resources. When patients in remote areas are in urgent need of medical care, the low latency of $5 \mathrm{G}$ allows doctors to deliver real-time treatment plans to patients remotely. Existing cases show that it is possible for doctors to perform surgery for patients at a distance. Traditional medical equipment communication has disadvantages such as delay and slow data processing. We use 5G technology to implement uploading to the cloud platform and artificial intelligence to analyze data and timely transmit it to relevant departments, which also has positive significance for the development of China's medical cause. Meanwhile, network information and scientific communication technology provide access to medical treatment and drugs in areas with poor health resources, providing online consultation, online diagnosis and treatment, and drug delivery to home, which greatly improves medical efficiency and reduces the cost of medical treatment for patients. In recent years, our country has been strongly encouraging online medical service, accelerating the settlement of medical treatment insurance in different provinces, promoting grading diagnosis, and providing information and technical support, in order to provide better service for patients by providing quality health care, optimizing the allocation of medical resources, and standardizing the medical service process of new solutions and new ideas. Also, the sharing of traditional medical resources should be actively provided so that they can be allocated effectively.

\subsection{Pay Attention to the Integration of Health Resources in} Primary Medical and Health Institutions and Promote the Improvement of Medical Service Quality. In the case of constant output, there is redundancy in the number of health institutions or sickbeds in several provinces, which is due to the excessive input of primary health care resources. At present, one of the biggest problems of many third-class hospitals (this designation is the medical institution level classified according to the current practice of the Measures for the Administration of the Hospital Grade in China) is the excessive pressure on patients seeking medical attention. This is largely related to patients' perceptions of medical care, many of whom have merely minor diseases but with a stronger preference for accessing health care in public hospitals with higher health care resources, resulting in a polarizing mix of resources. The shortage of health resources in large third-class hospitals and the redundancy of health resources in primary medical and health institutions are not conducive to their reasonable allocation, and they also cause a large amount of resource waste. In recent years, China has been promoting the construction of medical union + medical community. 
The medical and health resources in a certain region should be integrated, and all health service institutions should be combined to form a medical system, so as to guide patients to seek medical treatment scientifically and reasonably, and select appropriate medical and health service institutions according to the patients' causes and symptoms for alleviating the serious problem of resource polarization. For regulating the structure and function of health care facilities in various regions [22], relevant government departments are required to focus on grassroots-level medical institutions' resource integration and service quality improvement, which are not only meant to increase investment in basic medical and health care but also to promote grassroots-level progress of medical technology, facilitate the introduction of advanced technology and talents for grassroots-level medical institutions, and strengthen the development of medical school proofreading health technical personnel at the grassroots level. Regional health planning and rational allocation of health resources should be carried out in accordance with local conditions, two-way patient referral system should be established and improved, and patient guidance should be strengthened, so as to improve the utilization efficiency of primary health resources and promote hierarchical diagnosis and treatment.

5.4. Improve the Medical Insurance System, Support and Encourage the Public to Run Hospitals, and Combine Rigid Government Guidance with Self-Regulation by the Market. In the final analysis, the allocation of health resources belongs to the category of health economics. Spontaneity is the most significant feature of the market and policy regulation is indispensable for promoting the reasonable allocation of health resources. Generally speaking, the policies formulated by the government have the characteristics of direction, programmatic, and mandatory, which have the significance of stabilizing the overall situation for speeding up the improvement of the medical security system and improving the effectiveness of public management service. Whether it is hard resources such as the number of medical institutions, sickbeds, medical and health manpower, or soft resources such as medical technology education, health information policy, and health regulations, or whether the medical institutions are public or private hospitals, the basic orientation of the government in the field of medical and health is the direction. As far as the current situation is concerned, private hospitals develop rapidly, but their comprehensive competitiveness is not strong with the weak strength and their operating efficiency is lower than that of public hospitals. We shall promote the combination of rigid government guidance and market self-regulation, encourage the society to run hospitals, relax the conditions for sino-foreign joint venture and cooperation in running hospitals, and create a good environment for the development of private hospitals. Meanwhile, we should actively guide private hospitals and public hospitals to form an effective complementary cooperation mode and an effective supplement to public hospitals. In addition to the development of willing private capital, we should also allow overseas and foreign resources to come in, which undoubtedly would provide multiple ways for resource supplies. Thus, it can better coordinate the allocation of health resources.

The economic basis dictates superstructure, and for more economically disadvantaged areas, if the government has sufficient funding to support health finance, it is important to positively grasp the opportunities for economic and social development, promote economic transformation in order to improve economic vitality and economic strength, and ensure the continuous supply of local health services and the rational distribution of health resources. In addition, it is necessary to speed up building and perfect the suitable for different areas of health policy and health service pattern to promote the establishment of medical association, medical community model, and the practical implementation of hierarchical diagnosis and treatment. Multipronged policies should be adopted to solve the problem of uneven allocation of resources use and satisfy patients medical and health services in different levels of demand, which can realize the rational allocation of health resources and achieve the optimal combination of input-output.

\section{Data Availability}

The data used to support the findings of this study are available from the corresponding author upon request.

\section{Conflicts of Interest}

The authors declare that they have no conflicts of interest regarding the publication of this paper.

\section{Acknowledgments}

The project is sponsored by "Liaoning BaiQianWan Talents Program.”

\section{References}

[1] Y. Ge and X. Huang, "On the reasonable utilization of health resources from the "neonatal deaths incident", Chinese Medical Ethics, vol. 23, no. 2, pp. 112-113, 2010.

[2] P. Fang, R. Hu, and Q. Han, "Effects of healthcare reform on health resource allocation and service utilization in 1110 Chinese county hospitals: data from 2006 to 2012," The International Journal of Health Planning and Management, vol. 32, no. 4, pp. 400-415, 2017.

[3] E. Jordi, C. Pley, M. Jowett, G. J. Abou Jaoude, and H. Haghparast-Bidgoli, "Assessing the efficiency of countries in making progress towards universal health coverage: a data envelopment analysis of 172 countries," BMJ Global Health, vol. 5 , no. $10,2020$.

[4] T. Madjid, N. S. Salman, and H. F. Kholghabad, "An integrated quality and resilience engineering framework in healthcare with $Z$-number data envelopment analysis," Health Care Management Science, vol. 24, pp. 768-785, 2021.

[5] L. Jing, Z. Cheng, and J. Yao, "Health resources allocation efficiency assessment of clinical department in hospital based on DEA," Chinese Hospitals, vol. 22, no. 2, pp. 30-32, 2018. 
[6] K. Zhu, W. Liang, X. Wang, F. Shi, and D. Li, "Efficiency evaluation of basic public health service projects of community health service organizations in Zhuhai city based on data envelopment analysis," Modern Medicine \& Health, vol. 36, no. 12, pp. 1781-1784, 2020.

[7] T. Pang, B. Wei, and Q.-m. Feng, "Study on efficiency characteristics and changes of Guangxi municipal maternal and child health hospitals based on DEA," Maternal and Child Health Care of China, vol. 35, no. 13, pp. 2348-2351, 2020.

[8] N. Darabi, A. Ebrahimvandi, N. Hosseinichimeh, and K. Triantis, "A DEA evaluation of U.S. states' healthcare systems in terms of their birth outcomes," Expert Systems with Applications, vol. 182, Article ID 115278, 2021.

[9] B. Coluccia, D. Valente, G. Fusco, F. Leo, and D. Porrini, "Assessing agricultural eco-efficiency in Italian regions," Ecological Indicators, vol. 116, Article ID 106483, 2020.

[10] J. Bi and Z. Wang, "Evaluation of data envelopment analysis efficiency in tertiary hospitals in Jiangsu province," Acta Universitatis Medicinalis Nanjing, vol. 18, no. 3, pp. 230-233, 2018.

[11] P. Zhang, W. Deng, K. Chang, L. Wu, and S. Mao, "Analysis and research on health resource allocation efficiency of traditional Chinese medicine hospital based on data envelopment method," Modernization of Traditional Chinese Medicine and Materia Materia-World Science and Technology, vol. 21, no. 8, pp. 1687-1693, 2019.

[12] Z. Luo, "Evaluation of health resource allocation efficiency in Guangdong province based on data envelopment analysis," Chinese Journal of Health Statistics, vol. 30, no. 5, pp. 727-729, 2013.

[13] Y. Li, L. Yue, L. Guo et al., "Analysis and evaluation of medical service resource allocation efficiency of traditional Chinese medicine hospitals in Henan province based on DEA and malmquist index," Chinese Journal of Health Statistics, vol. 36, no. 5, pp. 710-712, 2019.

[14] L. Liang, Y. Wang, X. Wang et al., "Allocation efficiency of basic public health resources in Tianjin based on super-efficiency DEA," Chinese Rural Health Service Administration, vol. 40, no. 4, pp. 246-250, 2020.

[15] Q. Liu and J. Hao, "Efficiency evaluation of public health expenditure in China based on three-stage DEA malmquist," Statistics \& Decision, vol. 37, no. 21, pp. 154-158, 2021.

[16] Y. Li, "Study on the efficiency of public health expenditure and its influencing factors in Luoyang," Modern Business, vol. 36, no. 26, pp. 90-92, 2019.

[17] X. Qu, C. Cai, and Y. Wu, "Evaluation on health resource allocation and service utilization efficiency in Wuhan city in 2017 based on data envelopment analysis," Journal of Preventive Medicine Information, vol. 36, no. 2, pp. 133-136, 2020.

[18] Y. Chen, X. Liu, S. Dong, and H. Li, "Total factor productivity of provincial health care delivery in China," Chinese Health Resources, vol. 23, no. 2, pp. 122-129, 2020.

[19] S. Yang and S. Tian, "Analysis of health resource allocation efficiency of township hospitals in China," Journal of Physics: Conference Series, vol. 1774, no. 1, 2021.

[20] T. Xu and R. Yang, "Analysis on the measurement and influencing factors of China's health human resources equalization-an empirical study based on provincial panel data from 2012 to 2016," Health Economics, vol. 36, no. 6, pp. 13-16, 2019.

[21] N. Xu, Q. Hu, L. Zhang, and R. Tang, "Analysis of health resource allocation and its spatial variation in China," Journal of Medical Information, vol. 34, no. 21, pp. 17-20, 2021.
[22] S. Liu and Y. Liu, "Analysis of distribution and utilization of medical resources in different layers of Chengdu under the background of graded diagnosis and treatment," The Chinese Health Service Management, vol. 37, no. 5, pp. 364-367, 2020. 